\title{
CAT 2010: Ideas before their time: Connecting the past and present in computer art
}

Computer Art and Technocultures AHRC Project

3 February 2010

London

Editors:

Nick Lambert

Jeremy Gardiner

Francesca Franco 


\section{Abstract}

The symposium 'Ideas Before Their Time: Connecting the Past and Present in Computer Art' examines the ideas and technologies of computer-based art. Many intriguing concepts have emerged in computer art over the past 50 years. Some have been brought to light in the archives examined by the Computer Art and Technocultures Project at Birkbeck and the Victoria \& Albert Museum. With the current exhibitions of computer art, 'Decode' and 'Digital Pioneers' ongoing at the V\&A, this is a timely look at the area. Speakers from all areas of computer art, including practitioners, curators and historians, discuss the past, present and future of this area.

This conference is sponsored by:

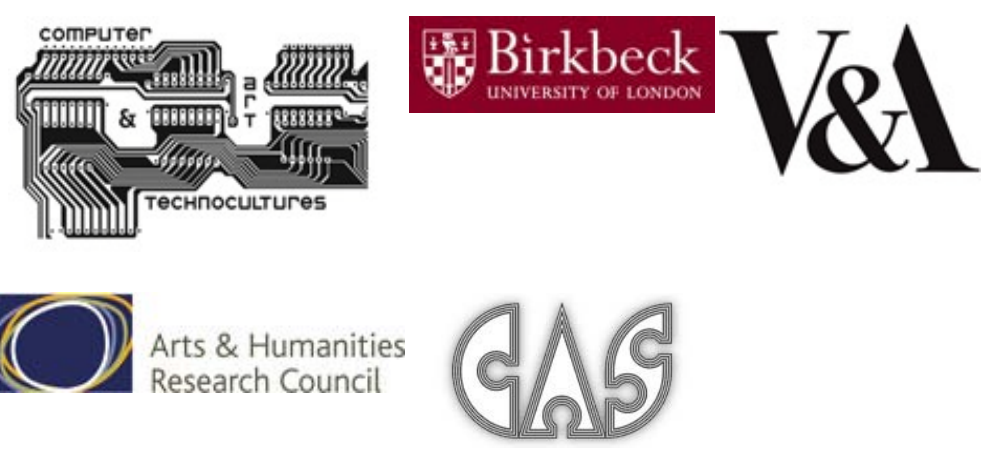




\section{Full Synopsis}

There is a mine, a treasure trove, a hoard - I cannot emphasize this too strongly - of art ideas that emerged in the early decades of computer that still have not remotely been explored. We know how this happens. The next big thing comes along and the Zeitgeist has its demands: things get left behind...

- Brian Reffin-Smith, "From 0 to 1", White Heat Cold Logic, p388

\section{THE SYMPOSIUM}

Taking Brian Reffin-Smith's quote as an inspiration, we aim to explore the ideas that have arisen over the lifetime of "computer art" since the 1960s. Over the past four decades, computer artists have innovated in significant ways but many of the concepts they explored were never taken to their conclusion. Primitive technologies and changing art practices consigned many of these ideas to obscurity. It was for this reason that we invited Brian to give the Keynote and happily he has obliged, taking an overview of the situation of computer art and arguing that 'Perhaps we should at least mentally redefine computer arts as being made by, with, or because or in spite of the computer.'

Brian insists that the digital arts should explore entirely new areas rather than revisiting what other artforms have already done: 'It is the difficult, the problematic in computer-based arts that we should keep, rediscover, re-explore. I think we often misunderstood what art was.'

This gets close to the core of what 'computer art' might actually be, a question that has had a central place in the research of the CACHe and CAT AHRC Projects. The questions surrounding the idea of a specific 'computer art' include the following:

1. What is the computer medium? Is it the partly illusory, partly real space conjured from mathematical coordinates as depicted on the monitor? Is it the process-based dynamic 'operational space' evoked by writing and running software? Or perhaps the conceptual and informational space entered by the artist working with the computer?

2. What is the computer's most important contribution to visual art? Does it come from the synaesthetic potential of combining the tools for 2D and 3D imagery, movies and sound in one interactive package? Does it derive from the promises of artificial intelligence with the computer functioning as a semiintelligent assistant, if not a full-blown creative agent in its own right? Is it the interconnectivity of practitioners and public achieved through the Net and Web 2.0? Or is it rather the conceptual aspects of computation and information that caused the pioneers to explore early computers for art?

3. Why did the first generation of computer art pioneers turn to the computer? Was it an inevitable development and if so does it demonstrate an urge to 'colonise' new spaces with creative activity, in a manner similar to our forebears working on cave walls and sheets of bark to make symbolic and depictive imagery? Did it all derive from the same source or were there a number of routes into early computer art? And could "computer art" be described as an art movement per se, or was this only a feature of the early days when numerous practitioners subscribed to a similar set of values?

4. The repertoire of computer output has steadily increased from plotter drawings to screen-based imagery, to large-scale projections and most recently to 3D printing, not forgetting computercontrolled audio-visual installations and robots. How are these new forms of output impacting the 
form of computer art, not to mention its perception and reception? As we have discovered during our documentary projects such as CACHe and CAT, computer art that most closely approximates traditional paper-based art is most easily conserved. Yet even these prints are the result of dynamic software processes.

5. Computer art was one of the earliest manifestations of digital imagery and many pioneers were instrumental in developing modern computer graphics. The computer has now become the primary image-creation tool across a broad swathe of industries, from film to television to graphic design to architecture. Peoples' daily engagement with digital imagery (and sound) in the context of digital devices has risen exponentially over the past decade. With the rise of augmented reality delivered via mobile phones, the digital now has a direct relation to our physical spaces as well. This entire structure of personal engagement with data might be termed 'technoculture' as it has a definite cultural impact. Where then does 'computer art' sit with regard to this emerging area, to which it contributes but still sits somewhat apart as 'art'?

To explore these ideas further, the Birkbeck team of the Computer Art and Technocultures AHRC Project have organised the symposium into five areas. Computer Art \& Cybernetics, Computer Art \& Time, Computer Art \& Space, Computer Art \& Output and Computer Art \& Technocultures. Each of these includes practitioners, curators, theorists, archivists and historians examining the concepts of Computer Art in relation to the questions posed above. 


\section{Editors}

This conference was edited by:

Nick Lambert - www.lambertsblog.co.ukl, Dr Nick Lambert is Researcher in Digital Media Art at the Department of History of Art and Screen Media at Birkbeck. He is Principal Investigator on the CAT Project and was previously Research Fellow of CACHe (Computer Arts, Contexts, Histories etc). He also lectures on the BA and MA History of Art courses at Birkbeck. Nick has been researching computer art since the mid-1990s and completed his DPhil thesis A Critical Examination of 'Computer Art': its History and Application in 2003. He is also part of the organising committee for EVA London and is Secretary of the Computer Arts Society.

Jeremy Gardiner - www.lightyearsprojects.org, Professor Jeremy Gardiner is Senior Research Fellow on the CAT Project and a former Harkness Fellow of the Media Lab at the Massachusetts Institute of Technology. He has received a New York Foundation for the Arts Fellowship, a NESTA grant and a Prix Ars Electronica honorary mention. He was a founding member of the Computer Graphics department at Pratt Institute of Art and Design, New York and Director of CyberArts at the New World School of the Arts, University of Florida. Recent projects include 'Imaginalis', a survey of new work, at the Chelsea Art Museum, New York City in 2009. His forthcoming exhibition 'A Panoramic View' opens at Pallant House, Chichester in early 2010.

Francesca Franco - www. francescafranco.net, Francesca Franco is Research Fellow on the AHRC funded project 'Computer Art \& Technocultures' (CAT) at Birkbeck College and the Victoria \& Albert Museum. She is a lecturer at the Department of History of Art and Screen Media at Birkbeck, where she teaches Critical Approaches to the History of Art. She is currently completing her PhD in History of Art on the relationship between art, technology and politics in the context of the Venice Biennale, 1966-1986, at Birkbeck. She has been sitting on the editorial board of Computers and the History of Art (CHArt) since 2005. 


\section{Papers:}

\section{Keynotes}

Brian Reffin-Smith Post Computer Art - Ontological Undecidability and the Cat with Paint on its

Paws http://dx.doi.org/10.14236/ewic/CAT2010.1

Session 1: Computer Art \& Cybernetics

Douglas Dodds Digital Pioneers: Computer-generated Art from the V\&A's Collections http://dx.doi.org/10.14236/ewic/CAT2010.2

Stroud Cornock The Interactive Art System http://dx.doi.org/10.14236/ewic/CAT2010.3

Ernest Edmonds and Francesca Franco Art of Conversation http://dx.doi.org/10.14236/ewic/CAT2010.4

Darko Fritz The Computer-Generated Artworks of Vladimir Bonačić http://dx.doi.org/10.14236/ewic/CAT2010.5

\section{Session 2: Computer Art \& Time}

George Mallen On the Relationship of Computing to the Arts and Culture - an Evolutionary Perspective http://dx.doi.org/10.14236/ewic/CAT2010.6

Frieder Nake Paragraphs on Computer Art, Past and Present http://dx.doi.org/10.14236/ewic/CAT2010.7

Richard Wright Program, Be Programmed or Fade Away: Computers and the Death of Constructivist Art http://dx.doi.org/10.14236/ewic/CAT2010.8

Helen Plumb Impermanent Art - the Essence of Beauty in Imperfection http://dx.doi.org/10.14236/ewic/CAT2010.9

\section{Session 3: Computer Art \& Space}


Nick Lambert The Computer as a Dynamic Medium http://dx.doi.org/10.14236/ewic/CAT2010.10

Bonnie Mitchell The Immersive Artistic Experience and the Exploitation of Space http://dx.doi.org/10.14236/ewic/CAT2010.11

Michael O'Rourke Redefining Sculpture Digitally http://dx.doi.org/10.14236/ewic/CAT2010.12

Robin Baker The New Ravensbourne $\quad$ http://dx.doi.org/10.14236/ewic/CAT2010.13

\section{Session 4: Computer Art \& Output}

Paul Coldwell Computer Art \& Output the Impassive Line http://dx.doi.org/10.14236/ewic/CAT2010.14

Jeremy Gardiner The Digital Atelier: How Substractive Technologies Create New Forms http://dx.doi.org/10.14236/ewic/CAT2010.15

Isaac Kerlow Digital Physicality: Printmaking http://dx.doi.org/10.14236/ewic/CAT2010.16

Jane Prophet Models, Maquettes and Art Objects: Making Data Physical http://dx.doi.org/10.14236/ewic/CAT2010.17

\section{Session 5: Computer Art \& Technocultures}

Maria Chatzichristodoulou Curating Technocultures

http://dx.doi.org/10.14236/ewic/CAT2010.18

David Garcia Networks of Freedom: Networks of Control http://dx.doi.org/10.14236/ewic/CAT2010.19

Sue Gollifer The Changing Nature of Artists' Practice http://dx.doi.org/10.14236/ewic/CAT2010.20

Bruce Wands Creating Continuity Between Computer Art History and Contemporary Art http://dx.doi.org/10.14236/ewic/CAT2010.21 